\title{
Effects of Post-weld Heat Treatment on Microstructure, Mechanical Properties and the Role of Weld Reinforcement in 2219 Aluminum Alloy TIG-Welded Joints
}

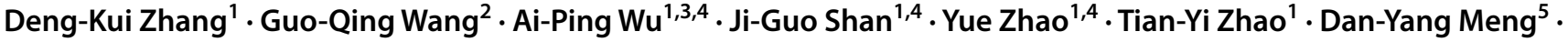 \\ Jian-Ling Song ${ }^{5} \cdot$ Zhong-Ping Zhang ${ }^{5}$
}

Received: 4 August 2018 / Revised: 5 November 2018 / Published online: 8 January 2019

(c) The Chinese Society for Metals (CSM) and Springer-Verlag GmbH Germany, part of Springer Nature 2019

\begin{abstract}
In as-welded state, each region of 2219 aluminum alloy TIG-welded joint shows different microstructure and microhardness due to the different welding heat cycles and the resulting evolution of second phases. After the post-weld heat treatment, both the amount and the size of the eutectic structure or $\theta$ phases decreased. Correspondingly, both the $\mathrm{Cu}$ content in $\alpha-\mathrm{Al}$ matrix and the microhardness increased to a similar level in each region of the joint, and the tensile strength of the entire joint was greatly improved. Post-weld heat treatment played the role of solid solution strengthening and aging strengthening. After the post-weld heat treatment, the weld performance became similar to other regions, but weld reinforcements lost their reinforcing effect on the weld and their existence was more of an adverse effect. The joint without weld reinforcements after the post-weld heat treatment had the optimal tensile properties, and the specimens randomly crack in the weld zone.
\end{abstract}

Keywords 2219 Aluminum alloy · Tungsten inert gas arc welding · Post-weld heat treatment · Weld reinforcement · Digital image correlation technique

\section{Introduction}

Precipitation-strengthened 2219 aluminum alloy has been widely used in the aviation and aerospace industries, due to its unique combination of multiple properties, such as

Available online at http://link.springer.com/journal/40195

Guo-Qing Wang

guoqingwang211@sohu.com

$\triangle$ Ai-Ping Wu

wuaip@ @singhua.edu.cn

1 Department of Mechanical Engineering, Tsinghua University, Beijing 100084, China

2 China Academy of Launch Vehicle Technology, Beijing 100076, China

3 State Key Laboratory of Tribology, Tsinghua University, Beijing 100084, China

4 Key Laboratory for Advanced Materials Processing Technology, Ministry of Education, Tsinghua University, Beijing 100084, China

5 Tianjin Long March Launch Vehicle Manufacturing Co., Ltd., Tianjin 300462, China excellent mechanical properties, weldability and stress corrosion resistance. Therefore, the research on 2219 aluminum alloy has become a hot spot [1-5].

Although electron beam welding (EBW), friction stir welding (FSW) and variable polarity plasma arc welding (VPPAW) and other methods have great advantages in welding aluminum alloys [6-12], the tungsten inert gas (TIG) arc welding is still the most common welding method in aerospace production lines due to its flexible operation, good weld formation and low cost. Considering that the combination of direct current tungsten inert gas (DCTIG) arc welding and pulse variable polarity tungsten inert gas (VPTIG) arc welding is often applied in the actual products $[13,14]$, we choose the joint obtained from this welding technique as the object of this study.

Unexpectedly, the tensile strength of the TIG-welded joint is always severely reduced (only achieves 50\%-60\% of the strength compared to the base metal), which would compromise the safety of actual service products $[15,16]$. As is well known, the TIG-welded joint contains weld zone (WZ), partially melted zone (PMZ), overaged zone (OAZ) and heat-affected zone (HAZ), and the mechanical properties of these regions are lower than those of the base metal due 
to the weakened microstructures caused by the solidification segregation and the evolution of strengthening phases. It is feasible to regulate the weakened microstructure through the post-weld heat treatment method, and some research results in this field have been reported until now [5, 15]. The main concern of these studies is the improvement in the tensile strength of the entire joint. However, not too much attention is paid to the microstructure evolution and the tensile strain distribution in each region of the joint. The study of microstructure evolution and tensile strain distribution is meaningful, which can provide a good theoretical explanation for the improvement in the tensile strength of the welded joints.

Moreover, WZ is the weakest region of the joint. The strength shortage of WZ is often offset by the weld reinforcements in actual welding products [17]. However, the microstructure in WZ has been regulated through the postweld heat treatment, the mechanical properties of WZ are no longer the weakest, and the existence of weld reinforcements could be more of an adverse effect because they induce the stress concentration around the weld toe. Furthermore, after the post-weld heat treatment, what role the weld reinforcements play should be paid attention to. In this area, research is still lacking.

Two studies in this work are conducted: (1) the effect of the post-weld heat treatment on the microstructure and mechanical properties of the TIG-welded joint focusing on the microstructure evolution in each region of the joint and (2) the role of weld reinforcements after the post-weld heat treatment focusing on the strain distribution in each region of the joint.

\section{Experimental}

The base material was 2219-C10S aluminum alloy plate with a dimension of $300 \mathrm{~mm} \times 150 \mathrm{~mm} \times 10 \mathrm{~mm}$. The $\mathrm{C} 10 \mathrm{~S}$ alloy was prepared by solution heat treatment and cold working under deformation of approximately $10 \%$, followed by artificial aging [18]. The filler metal was ER2325 (Al-Cu-Mn). The nominal chemical compositions of base metal and filler metal are given in Table 1.

The butt-welded plate joint was prepared by a threelayer welding process on one side. The first layer adopted DCTIG helium arc welding without grooves or filler metal. The second and the third layers adopted pulse VPTIG argon arc welding with ER2325 filler metal. Two buttwelded plate joints (1\# and 2\#) were obtained in this work,
Table 2 Welding process parameters of the two butt-welded plate joints ( $\eta$ represents the power factor of the arc)

\begin{tabular}{llll}
\hline $\begin{array}{l}\text { Butt-welded } \\
\text { plate joint }\end{array}$ & Welding layer & $\begin{array}{l}\text { Welding } \\
\text { heat input, } \eta \\
\left(\mathrm{J} \cdot \mathrm{cm}^{-1}\right)\end{array}$ & $\begin{array}{l}\text { Wire feed- } \\
\text { ing speed } \\
\left(\mathrm{mm} \cdot \mathrm{min}^{-1}\right)\end{array}$ \\
\hline $1 \#$ & First layer & 12,825 & - \\
& Second layer & 29,314 & 600 \\
& Thirdlayer & 37,620 & 800 \\
& First layer & 12,825 & - \\
& Second layer & 29,314 & 400 \\
& Third layer & 33,094 & 800 \\
\hline
\end{tabular}

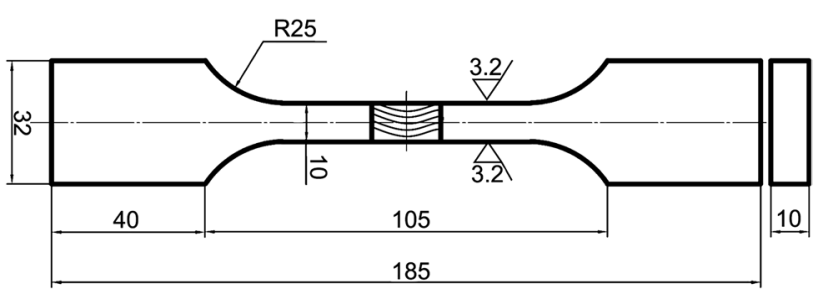

Fig. 1 Dimensions of tensile specimen (unit: $\mathrm{mm}$ )

and their specific welding process parameters are shown in Table 2. Five specimens were cut from each butt-welded plate joint perpendicular to the welding direction. One of them was used for microstructure observation and microhardness test before and after the post-weld heat treatment. The other four specimens were directly cut into a shape of tensile specimen according to GB/T 228.1-2010 with the gauge length of $50 \mathrm{~mm}$, and the dimensions of tensile specimen are shown in Fig. 1. The specimens were named as 1-1\#, 1-2\#, 1-3\#, 1-4\#, and 2-1\#, 2-2\#, 2-3\#, 2-4\#, respectively.

Two tensile specimens from each butt-welded plate joint (1-3\#, 1-4\#, and 2-3\#, 2-4\#) were selected for the post-weld heat treatment. It was remarkable that the reinforcements of 1-4\# and 2-4\# specimens were flattened. The specific postweld heat treatment process was conducted following "solid solution + artificial aging," as shown in Fig. 2. The solution treatment process was as follows: heating from room temperature to $535^{\circ} \mathrm{C}$ (the heating rate was $200{ }^{\circ} \mathrm{C} / \mathrm{h}$ ), then keeping at this temperature for $90 \mathrm{~min}$ and then water quenching (the transfer time was less than $5 \mathrm{~s}$ ). The artificial aging process was as follows: heating from room temperature to $175^{\circ} \mathrm{C}$ (the heating rate was $100{ }^{\circ} \mathrm{C} / \mathrm{h}$ ), then keeping at this temperature for $12 \mathrm{~h}$ and then followed by furnace cooling.
Table 1 Chemical compositions of 2219 aluminum alloy and ER2325 filler metal (wt.\%)

\begin{tabular}{lllllllllll}
\hline Alloy & $\mathrm{Si}$ & $\mathrm{Fe}$ & $\mathrm{Cu}$ & $\mathrm{Mn}$ & $\mathrm{Mg}$ & $\mathrm{Zn}$ & $\mathrm{Ti}$ & $\mathrm{Zr}$ & $\mathrm{V}$ & $\mathrm{Al}$ \\
\hline 2219 & 0.2 & 0.3 & $5.8-6.8$ & $0.2-0.4$ & 0.02 & 0.1 & $0.02-0.10$ & $0.10-0.25$ & $0.05-0.15$ & Bal. \\
2325 & - & - & $6.0-6.8$ & $0.2-0.4$ & - & - & $0.1-0.2$ & - & - & Bal. \\
\hline
\end{tabular}




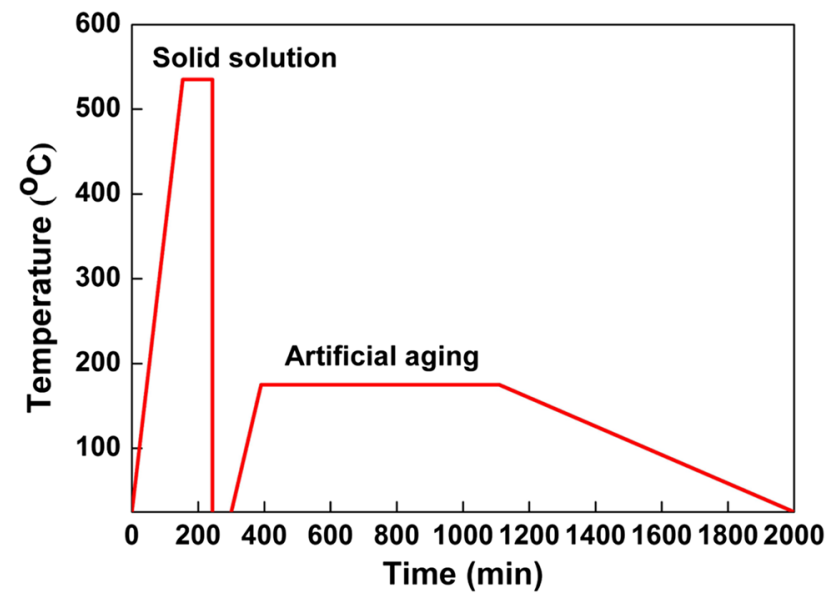

Fig. 2 Specific post-weld heat treatment process

After grinding and polishing, the specimens used for microstructure observation and microhardness test were etched in Keller's reagent for 10-15 s. Microstructure observation of the base metal and the cross section of the specimen were conducted by scanning electronic microscopy (SEM) and transmission electron microscopy (TEM). Microhardness test was conducted on an MH-3 Vickers hardness tester with a $1 \mathrm{~N}$ load and a holding time of $10 \mathrm{~s}$. For the tensile specimens, the tensile rate was $2 \mathrm{~mm} / \mathrm{min}$. Digital image correlation (DIC) technique was used to capture the strain distribution during the tensile test. Fracture path observation of the fractured joints was conducted by optical microscopy (OM).

\section{Results}

\subsection{Microstructure}

The TEM images of 2219-C10S base metal are shown in Fig. 3. The bulk $\theta$ phases can be observed on the grain boundaries, the sizes of which are inconsistent (Fig. 3a), and the stable $\theta$ phases cannot contribute to the precipitation strengthening [19]. A large number of lamellar $\theta^{\prime}$ phases can be observed in the grain interior (Fig. 3b), and the metastable $\theta^{\prime}$ phases can play a role of precipitation strengthening [19]. The coarse rod-shaped or pancake-shaped $T$ phases also coexist in the aluminum alloy (Fig. 3c), and the $T$ phases are the impurity phases that can weaken the mechanical properties [20]. The electron diffraction spot patterns (Fig. 3d, e) can verify the presence of $\theta$ and $\theta^{\prime}$ phases in 2219-C10S aluminum alloy.

We selected four random points on base metal and conducted energy-dispersive spectrometry (EDS) analysis by using the SEM, and the $\mathrm{Cu} / \mathrm{Al}$ atomic mass ratios were 7.18/92.82, 7.77/92.23, 7.09/92.91 and 6.81/93.19, respectively. Based on the aluminum-copper alloy binary phase
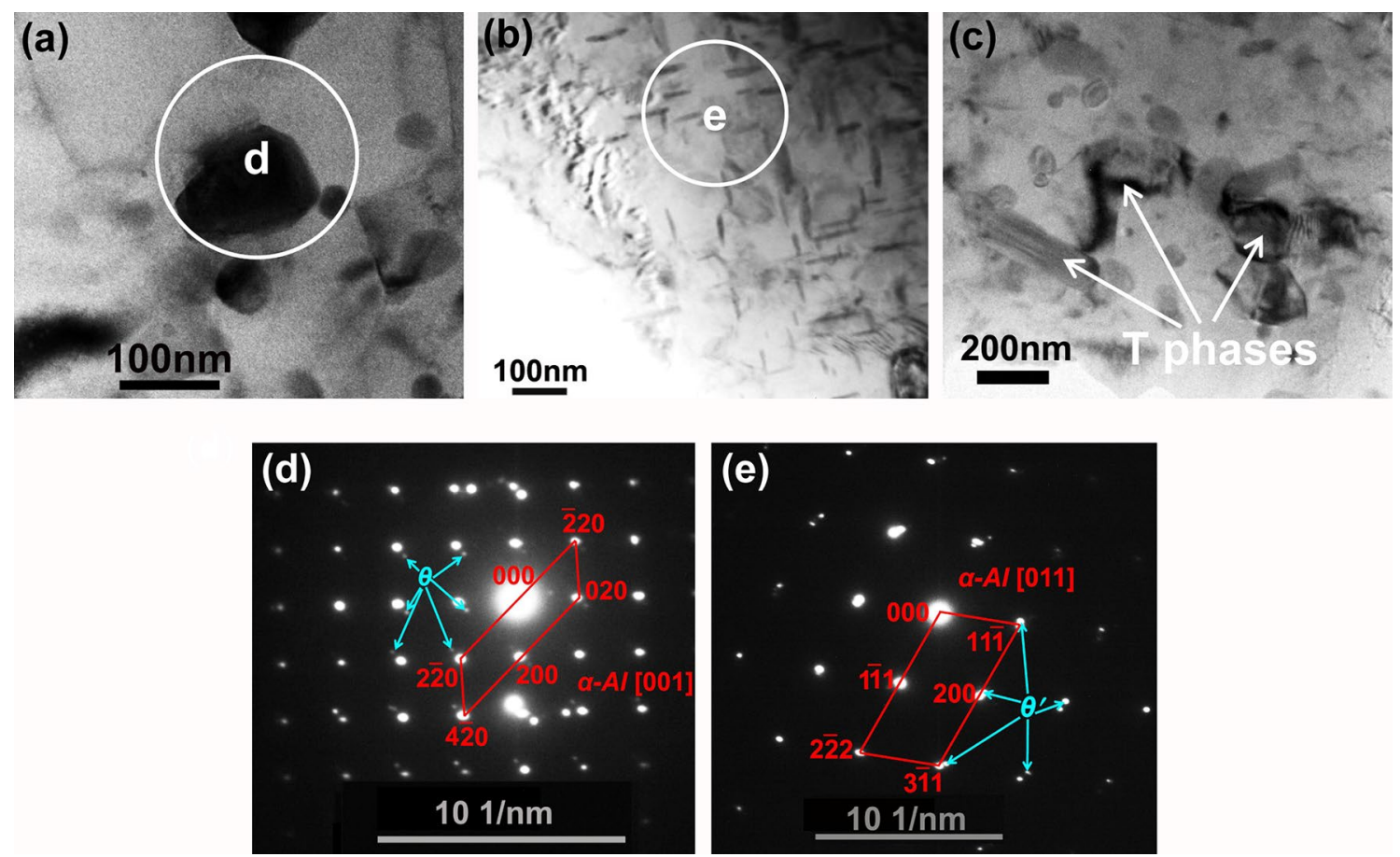

Fig. 3 TEM images of 2219-C10S aluminum alloy: a-c the microstructure of the different phase, respectively; d, e the selected area diffraction pattern from $\mathbf{a}, \mathbf{b}$, respectively 
diagram, the maximum solid solubility of $\mathrm{Cu}$ in $\alpha-\mathrm{Al}$ is 5.65 wt.\%. However, the average $\mathrm{Cu}$ content of the 2219$\mathrm{C} 10 \mathrm{~S}$ base metal is $7.21 \mathrm{wt}$.\%, which has exceeded the maximum solid solubility of $\mathrm{Cu}$ in $\alpha-\mathrm{Al}$. This is because a large number of $\theta^{\prime}$ phases exist in the base metal. The $\theta^{\prime}$ phase is too small (the thickness is $3.5-17 \mathrm{~nm}$, and the diameter is $85-700 \mathrm{~nm}$ ) to be observed in the SEM, and the $\mathrm{Cu} / \mathrm{Al}$ atomic mass ratios of four random points are the average compositions of $\theta^{\prime}$ and $\alpha-\mathrm{Al}$ [21].

The 1\# butt-welded plate joint was selected to discuss the microstructure evolution before and after the post-weld heat treatment. The microstructure of WZ before and after the post-weld heat treatment is shown in Fig. 4, and the EDS results are shown in Table 3. After the post-weld heat treatment, both the amount and the size of eutectic structure or $\theta$ phases are significantly reduced. Correspondingly, the $\mathrm{Cu}$ content in $\alpha$-Al matrix is significantly increased. It indicates that post-weld heat treatment plays a role of solid solution strengthening and aging strengthening.

The microstructure of joint's PMZ, OAZ and HAZ before and after the post-weld heat treatment is shown in Fig. 5. After the post-weld heat treatment, some large eutectic
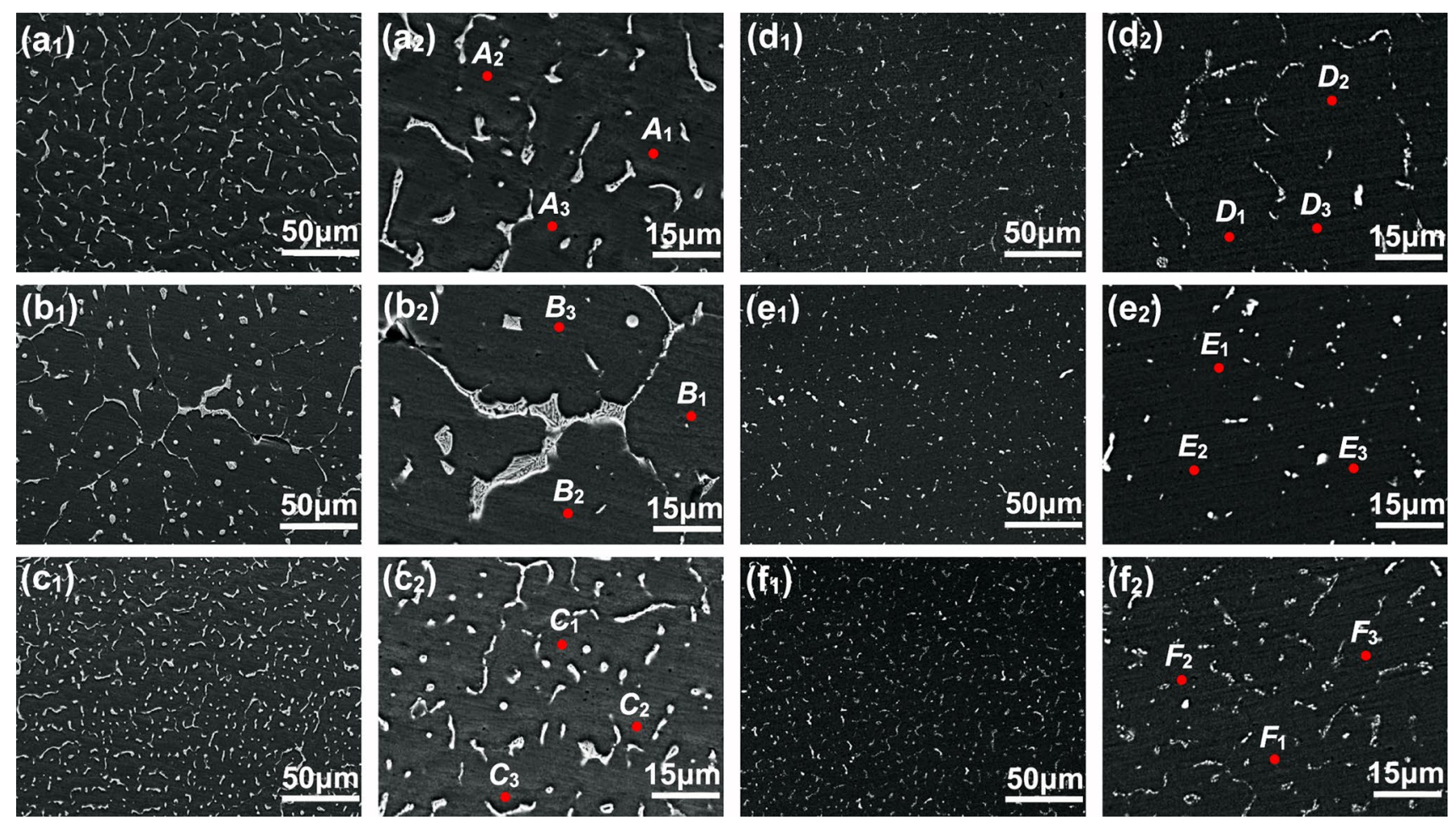

Fig. 4 Microstructure of WZ before and after the post-weld heat treatment: $\mathbf{a}_{1}, \mathbf{a}_{2}, \mathbf{b}_{\mathbf{1}}, \mathbf{b}_{\mathbf{2}}, \mathbf{c}_{\mathbf{1}}, \mathbf{c}_{\mathbf{2}}$ the upper, the middle and the lower layer of the WZ in as-welded state; $\mathbf{d}_{1}, \mathbf{d}_{2}, \mathbf{e}_{1}, \mathbf{e}_{2}, \mathbf{f}_{\mathbf{1}}, \mathbf{f}_{\mathbf{2}}$ the upper, the middle and the lower layer of the WZ after the post-weld heat treatment

Table 3 EDS analysis results of the $\alpha$-Al matrix in Fig. 4 (wt.\%)

\begin{tabular}{|c|c|c|c|c|c|c|c|c|c|}
\hline No. & $A_{1}$ & $A_{2}$ & $A_{3}$ & $B_{1}$ & $B_{2}$ & $B_{3}$ & $C_{1}$ & $C_{2}$ & $C_{3}$ \\
\hline \multirow[t]{2}{*}{$\mathrm{Cu}$} & 3.19 & 3.57 & 2.84 & 3.91 & 4.02 & 3.85 & 2.17 & 2.46 & 2.44 \\
\hline & Average: 3.20 & & & Average: 3.93 & & & Average: 2.36 & & \\
\hline \multirow[t]{2}{*}{$\mathrm{Al}$} & 96.81 & 96.43 & 97.16 & 96.09 & 95.98 & 96.15 & 97.83 & 97.54 & 97.56 \\
\hline & Average: 96.80 & & & Average: 96.07 & & & Average: 97.64 & & \\
\hline No. & $D_{1}$ & $D_{2}$ & $D_{3}$ & $E_{1}$ & $E_{2}$ & $E_{3}$ & $F_{1}$ & $F_{2}$ & $F_{3}$ \\
\hline \multirow[t]{2}{*}{$\mathrm{Cu}$} & 7.83 & 7.51 & 7.64 & 7.88 & 7.77 & 8.61 & 7.72 & 7.81 & 7.79 \\
\hline & Average: 7.66 & & & Average: 8.09 & & & Average: 7.77 & & \\
\hline \multirow[t]{2}{*}{$\mathrm{Al}$} & 92.17 & 92.49 & 92.36 & 92.12 & 92.23 & 91.39 & 92.28 & 92.19 & 92.21 \\
\hline & Average: 92.34 & & & Average: 91.91 & & & Average: 92.23 & & \\
\hline
\end{tabular}



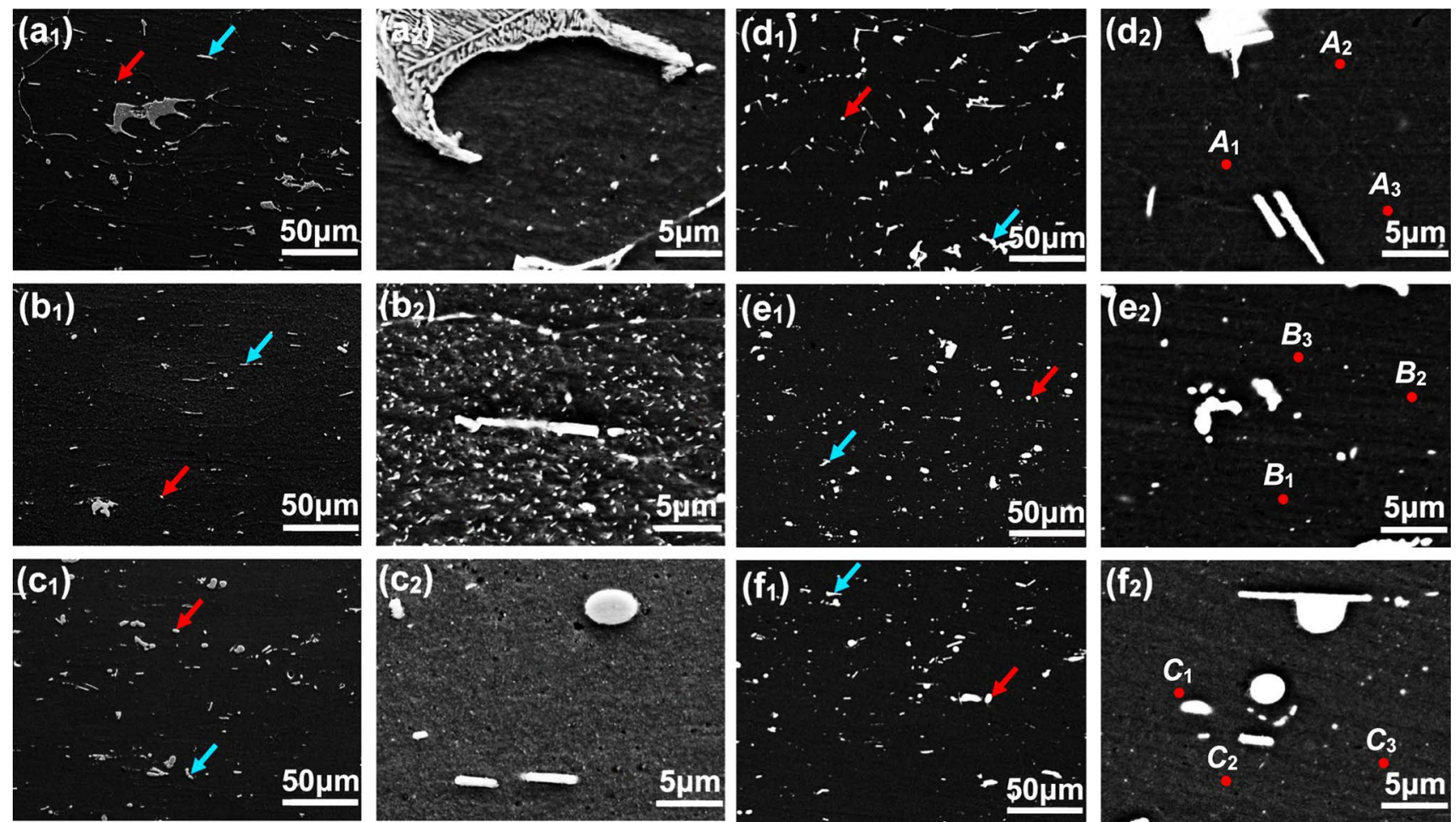

Fig. 5 Microstructure of joint's PMZ, OAZ, HAZ before and after the post-weld heat treatment: $\mathbf{a}_{1}, \mathbf{a}_{2}, \mathbf{b}_{1}, \mathbf{b}_{2}, \mathbf{c}_{1}, \mathbf{c}_{2}$ the region of PMZ, OAZ and HAZ in as-welded state; $\mathbf{d}_{1}, \mathbf{d}_{2}, \mathbf{e}_{1}, \mathbf{e}_{2}, \mathbf{f}_{\mathbf{1}}, \mathbf{f}_{2}$ the region of PMZ, OAZ and HAZ after the post-weld heat treatment

structures or $\theta$ phases have already been dissolved in PMZ. Meanwhile, a large number of coarsened $\theta$ phases have already been dissolved in OAZ. These behaviors could lead to the increase in $\mathrm{Cu}$ content in $\alpha$-Al matrix of the corresponding region. It is worth noting that both $\theta$ phase indicated by red arrows and $T$ phase indicated by blue arrows can be observed in each region before and after the postweld heat treatment, and the solution treatment does not dissolve some preexisting $\theta$ and $T$ phases, which is related to the limited solid solubility of $\mathrm{Cu}$ in aluminum. Based on the EDS results in Table 4, the $\mathrm{Cu}$ content of the $\alpha$-Al matrix in each region increases to a similar level after the post-weld heat treatment.

\subsection{Microhardness}

The microhardness distribution on transverse cross section of the joints before and after the post-weld heat treatment is shown in Fig. 6. For each joint in as-welded state, the hardness values from the minimum to the maximum appear in WZ, OAZ, PMZ and HAZ, successively. It indicates that the microstructure and mechanical properties of the transverse joint in as-welded state are inhomogeneous. For each joint after the post-weld heat treatment, the hardness values of each region significantly increase to approximately 140-150 $\mathrm{HV}_{0.1}$. It indicates that the microstructure and mechanical properties of the transverse joint after the post-weld heat treatment are homogeneous. In addition, as shown in Fig. 6a, b, 1\# joint has the larger front weld width and the shallower penetration depth of capping weld.

\subsection{Tensile Mechanical Properties}

Tensile curves and tensile properties of the welded joints are shown in Fig. 7 and Table 5.
Table 4 EDS analysis results of the $\alpha$-Al matrix in Fig. 5 (wt.\%)

\begin{tabular}{|c|c|c|c|c|c|c|c|c|c|}
\hline No. & $A_{1}$ & $A_{2}$ & $A_{3}$ & $B_{1}$ & $B_{2}$ & $B_{3}$ & $C_{1}$ & $C_{2}$ & $C_{3}$ \\
\hline \multirow[t]{2}{*}{$\mathrm{Cu}$} & 7.91 & 8.04 & 7.93 & 7.73 & 7.67 & 7.94 & 7.96 & 7.44 & 7.79 \\
\hline & Average: 7.96 & & & Average: 7.78 & & & Average: 7.73 & & \\
\hline \multirow[t]{2}{*}{$\mathrm{Al}$} & 92.09 & 91.96 & 92.07 & 92.27 & 92.33 & 92.06 & 92.04 & 92.56 & 92.22 \\
\hline & Average: 92.04 & & & Average: 92.22 & & & Average: 92.27 & & \\
\hline
\end{tabular}




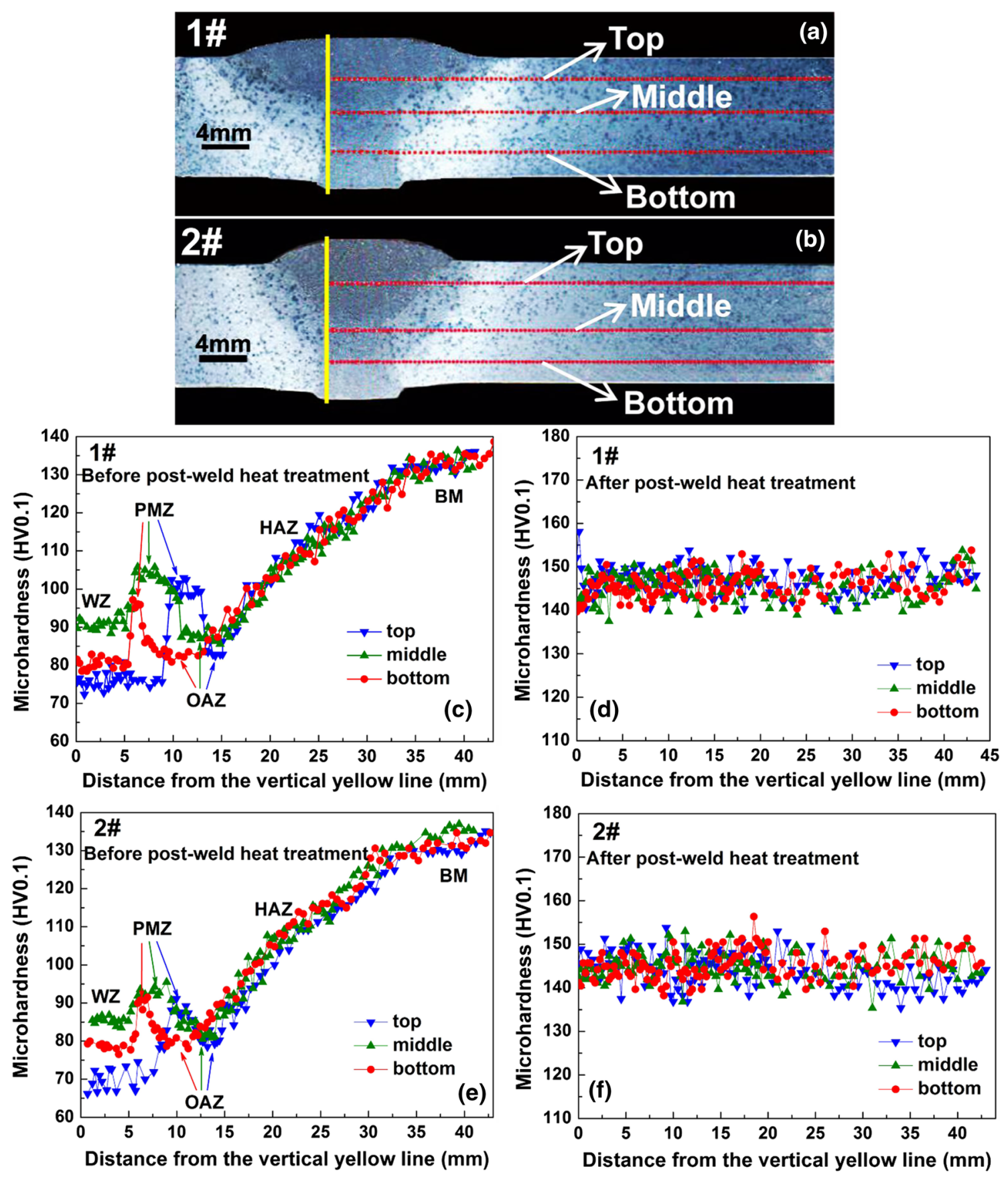

Fig. 6 Microhardness distribution on transverse cross section of the joints: $\mathbf{a}, \mathbf{b}$ the locations of hardness testing of $1 \#$ and $2 \#$ joints; $\mathbf{c}$, $\mathbf{d}$ the hardness distribution of $1 \#$ joint before and after the post-weld

heat treatment; e, $\mathbf{f}$ the hardness distribution of $2 \#$ joint before and after the post-weld heat treatment

In as-welded state, the average tensile strength of $1 \#$ buttwelded plate joint (based on 1-1\# and 1-2\#) and 2\# buttwelded plate joint (based on 2-1\# and 2-2\#) is $310 \mathrm{MPa}$ and $274 \mathrm{MPa}$, respectively. Meanwhile, the average elongation is $7.8 \%$ and $3.8 \%$, respectively. The differences in mechanical properties of the two joints are mainly attributed to the different weld shapes. Our previous study found that the larger of the front weld width and shallower of the penetration depth of capping weld, the better mechanical properties the joint will achieve. Therefore, $1 \#$ joint has the better tensile strength and elongation.

After the post-weld heat treatment, 1\# joint (based on 1-3\#) and 2\# joint (based on 2-3\#) have very similar tensile strength, and their strength values are significant 

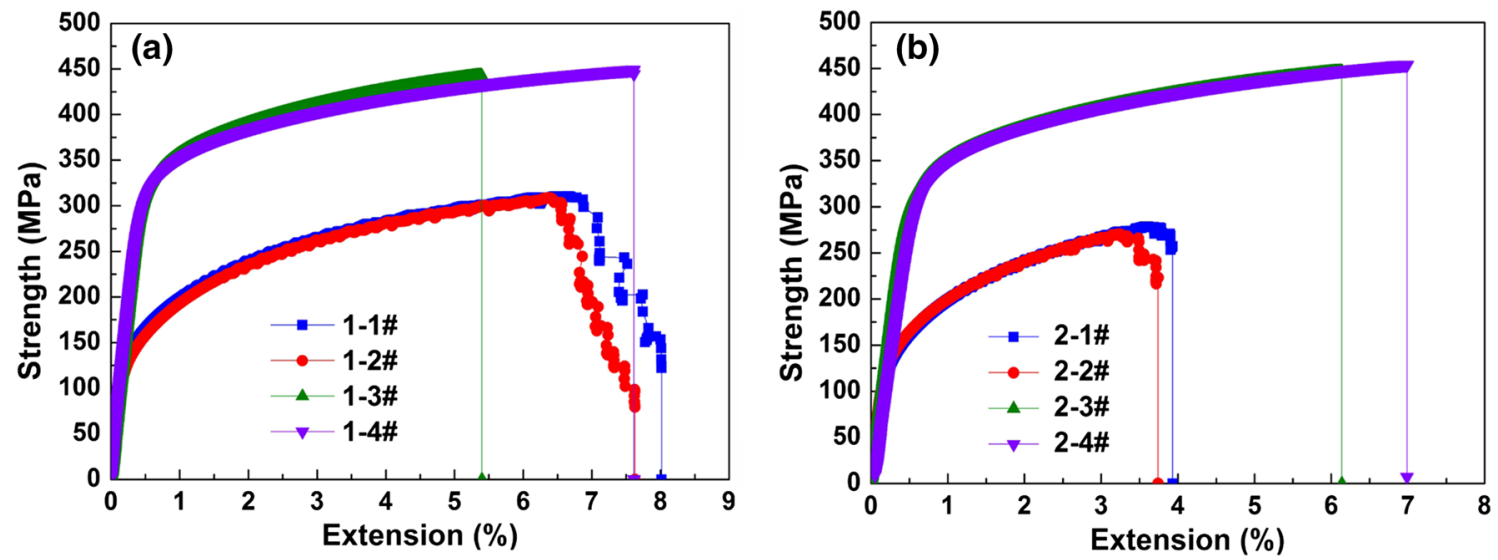

Fig. 7 Tensile curves of the welded joints

Table 5 Tensile properties of the welded joints

\begin{tabular}{llll}
\hline Samples & $\begin{array}{l}\text { Tensile strength } \\
(\mathrm{MPa})\end{array}$ & Elongation $(\%)$ & $\begin{array}{l}\text { Elongation } \\
\text { after fracture } \\
(\%)\end{array}$ \\
\hline $1-1 \#$ & 310 & 8.0 & 8.3 \\
$1-2 \#$ & 309 & 7.6 & 8.0 \\
$1-3 \#$ & 443 & 5.4 & 5.9 \\
$1-4 \#$ & 449 & 7.6 & 7.9 \\
$2-1 \#$ & 278 & 3.9 & 5.1 \\
$2-2 \#$ & 270 & 3.7 & 4.1 \\
$2-3 \#$ & 447 & 6.1 & 6.7 \\
$2-4 \#$ & 454 & 7.0 & 7.2 \\
\hline
\end{tabular}

1-1\#, 1-2\#, 2-1\#, 2-2\# are the tensile specimens in as-welded state; 1-3\# and 2-3\# are the tensile specimens after the post-weld heat treatment; $1-4 \#$ and 2-4\# are the tensile specimens without weld reinforcements after the post-weld heat treatment

higher than those of the as-welded state. The joint without weld reinforcements has the higher tensile strength and elongation (comparing 1-3\# with 1-4\#, or 2-3\# with $2-4 \#)$. It indicates that post-weld heat treatment results in the changes of the microstructure in each region of the joint, and these changes are beneficial. Meanwhile, weld reinforcements have lost the reinforcing effect on the weld after the post-weld heat treatment.

\section{Discussion}

Post-weld heat treatment causes the microstructure evolution and eventually leads to the changes in mechanical properties. We mainly analyze it from the following two aspects.

\subsection{Effects of Post-weld Heat Treatment on the Microstructure and Mechanical Properties}

According to the report in [22], the initial formation and dissolution temperature of $\theta^{\prime}$ phase are $280{ }^{\circ} \mathrm{C}$ and $300{ }^{\circ} \mathrm{C}$, respectively. Meanwhile, those of $\theta$ phase are $425^{\circ} \mathrm{C}$ and $470{ }^{\circ} \mathrm{C}$, respectively.

Before the post-weld heat treatment: In WZ, all the phases from the base metal are dissolved during the welding, and then, the non-equilibrium solidification leads to the precipitation of eutectic structure or $\theta$ phase. In PMZ, the peak temperature during the welding is about $543-643{ }^{\circ} \mathrm{C}$. All the $\theta^{\prime}$ and some $\theta$ phases from the base metal are dissolved, and then, the non-equilibrium solidification also leads to the precipitation of eutectic structure or $\theta$ phase. Therefore, eutectic structure and $\theta$ phase in different sizes can be observed in WZ and PMZ. In OAZ, the peak temperature during the welding is about $415-535{ }^{\circ} \mathrm{C}$. The $\theta^{\prime}$ phases become coarse, then dissolve and start to transform into $\theta$ phases. The dissolution and the coarsening behaviors of $\theta^{\prime}$ phases coexist. Therefore, the coarsening and the dense $\theta$ phases can be observed in OAZ. In HAZ, the peak temperature during the welding is about $319-415^{\circ} \mathrm{C}$, and the $\theta^{\prime}$ phases become coarse. However, $\theta^{\prime}$ phases are too small to be observed and only $\theta$ phases can be observed in HAZ. Moreover, $T$ phases from the base metal are not completely dissolved in PMZ, OAZ and HAZ. Therefore, partial $T$ phases can be observed in these regions. Microstructure evolution in different regions leads to different $\mathrm{Cu}$ contents in $\alpha$-Al matrix. Therefore, each region of the joint shows the different hardness values due to the different $\mathrm{Cu}$ content and different distribution of eutectic structure and strengthening phases.

After the post-weld heat treatment: Solution treatment temperature is $535^{\circ} \mathrm{C}$. A large number of $\theta$ and $\theta^{\prime}$ phases are 
dissolved in each region of the joint. The rapid quenching can prevent the precipitation of $\theta$ phases as much as possible. The artificial aging can cause the precipitation of a large number of $\theta^{\prime}$ phases and may be very few $\theta^{\prime \prime}$ phases $\left(\theta^{\prime}\right.$ and $\theta^{\prime \prime}$ phases are strengthening phases). Due to the similar $\mathrm{Cu}$ content in $\alpha$-Al matrix and the distribution of strengthening phases, the hardness values in each region of the joint increase to a similar level (approximately $140-150 \mathrm{HV}_{0.1}$ ). The tensile strength of the joint is greatly improved after the post-weld heat treatment due to the increased $\mathrm{Cu}$ content and number of strengthening phases in $\alpha$-Al matrix. It is noteworthy that $\theta$ or $T$ phases observed in each region are residual and undissolved during the post-weld heat treatment. The reason is that the $\mathrm{Cu}$ has a limited solubility in $\alpha$-Al according to the aluminum-copper binary phase diagram. The solution treatment cannot dissolve all the $\theta$ and $T$ phases. Meanwhile, the artificial aging temperature is only $175^{\circ} \mathrm{C}$ (far below $425^{\circ} \mathrm{C}$ ), and the $\theta$ phase cannot be precipitated.
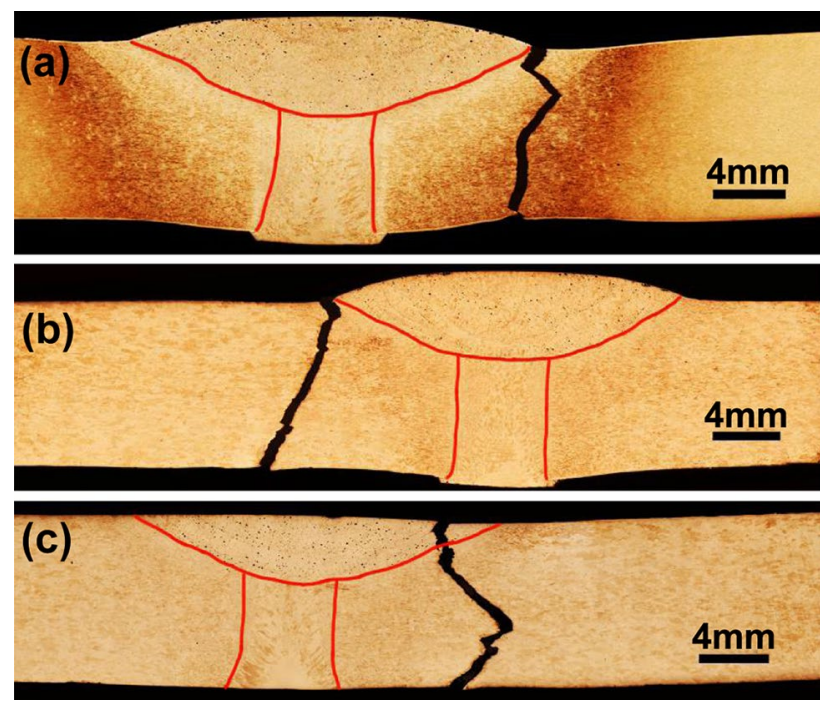

Fig. 8 Macroscopic morphology on transverse cross section of fractured joints: a 1-1\#, b 1-3\#, c 1-4\#

\subsection{Effects of Post-weld Heat Treatment on the Role of Weld Reinforcement}

Fracture path and morphology of the fractured joint are shown in Figs. 8 and 9. For the specimen in as-welded state (Figs. 8a, 9a) and the specimen after the post-weld heat treatment (Figs. 8b, 9b), the cracks initiate in the region near the front weld toe. The stress is more concentrated in the region near the weld toe, and the specimens are easy to crack there. However, for the specimen without weld reinforcements after the post-weld heat treatment (Figs. 8c, 9c), the crack initiates in the front WZ. Specimen without reinforcements gets no stress concentration. The specimen randomly cracks in the weld where there may be some pores and the pores become the crack initiation source. Combining the tensile properties in Table 5, 1-4\# specimens have better tensile properties than 1-3\# specimens, which indicates that weld reinforcements have lost the reinforcing effect on the weld after the post-weld heat treatment. WZ is no longer the weakest region in mechanical properties, and the existence of weld reinforcements can only be redundant and unfavorable.

The true strain distributions on the edge surface immediately before the fracture of the specimens are shown in Fig. 10. For the specimen in as-welded state (Fig. 10a), different regions show different strain distributions. The regions of OAZ and $\mathrm{WZ}$ have the maximum strain values, and weld reinforcements have the reinforcing effect on the weld. For the specimen after the post-weld heat treatment (Fig. 10b), WZ has become the region with the minimum strain values. The overall strain values of this specimen are lower than those of the specimen in as-welded state, indicating that it has better tensile mechanical properties. Unexpectedly, weld reinforcements cause a larger strain difference between WZ and PMZ (around the weld toe), and more concentrated stress may occur around the weld toe and then cause cracks to break easily from here. Meanwhile, postweld heat treatment makes the performance in each region of the joint similar. In particular, the WZ performance has been significantly improved. It can be implied that the reinforcing effect on WZ is no longer needed. The specimen
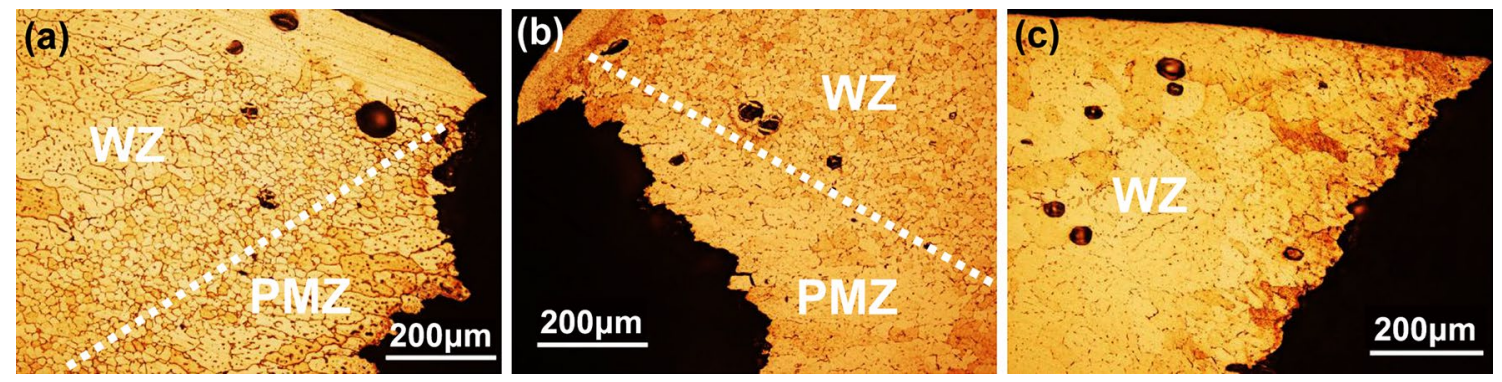

Fig. 9 Enlarged images of crack initiation region of fractured joints: a 1-1\#, b 1-3\#, c 1-4\# 

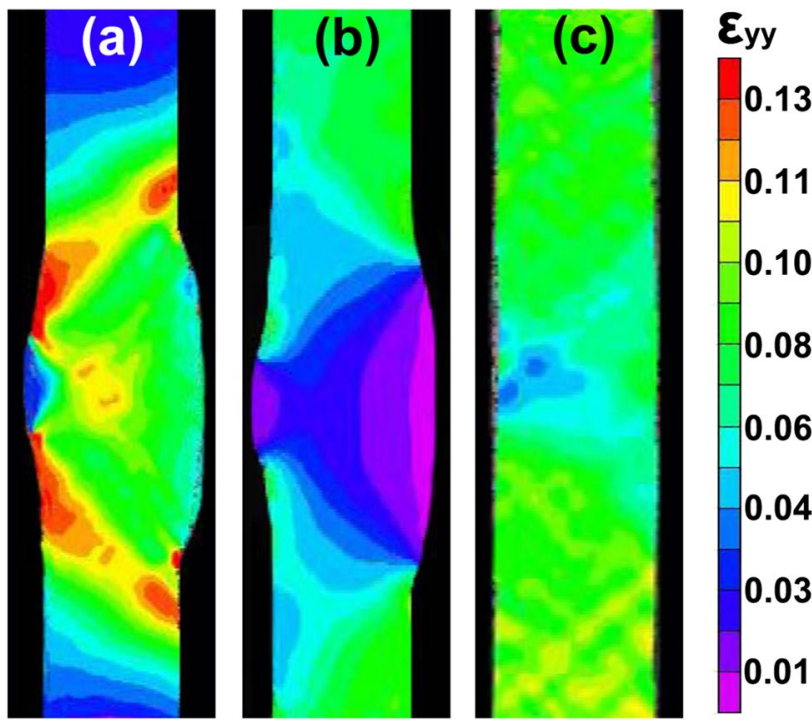

Fig. 10 True strain distributions on the edge surface immediately before the fracture: a 1-1\#, b 1-3\#, c 1-4\#

without weld reinforcements after the post-weld heat treatment is also studied (Fig. 10c). The minimum strain values also appear in WZ. However, the deformation in each region is the most uniform, indicating that it has the best tensile mechanical properties.

For the three specimens above, true strain curves of crack initiation points during the tensile test are shown in Fig. 11. The fracture strain value from the maximum to the minimum appears in 1-1\#, 1-3\# and 1-4\#, successively, which implies that the performance of crack initiation region from "soft" to "hard" appears in 1-1\#, 1-3\# and 1-4\#, successively.

The true strain distributions of specimens' edge surface under different stresses during the tensile test are shown in Fig. 12.

Under the stress of $300 \mathrm{MPa}$, the specimens before and after the post-weld heat treatment are compared. For the specimen in as-welded state (Fig. 12a), the tensile deformation is mainly concentrated in WZ and OAZ, and each region of the specimen shows the different deformation degree. However, for the specimens after the post-weld heat treatment (Fig. 12b, c), the tensile deformation in each region is the same and very slight (the strain value is less than $1 \%$ ). Post-weld heat treatment causes a lot of $\theta^{\prime}$ phases to be precipitated in $\alpha$-Al matrix. These tiny $\theta^{\prime}$ strengthening phases can cause complex stress fields and block the slipping of dislocations, and eventually, the specimens after the postweld heat treatment are strengthened and the strain values are reduced in each region. In addition, combining Fig. 7a, when the stress reaches $300 \mathrm{MPa}$, the specimen in as-welded state is in the yield stage. However, the specimens after the post-weld heat treatment are just in the elastic stage. It again proves that the microstructure and mechanical properties of

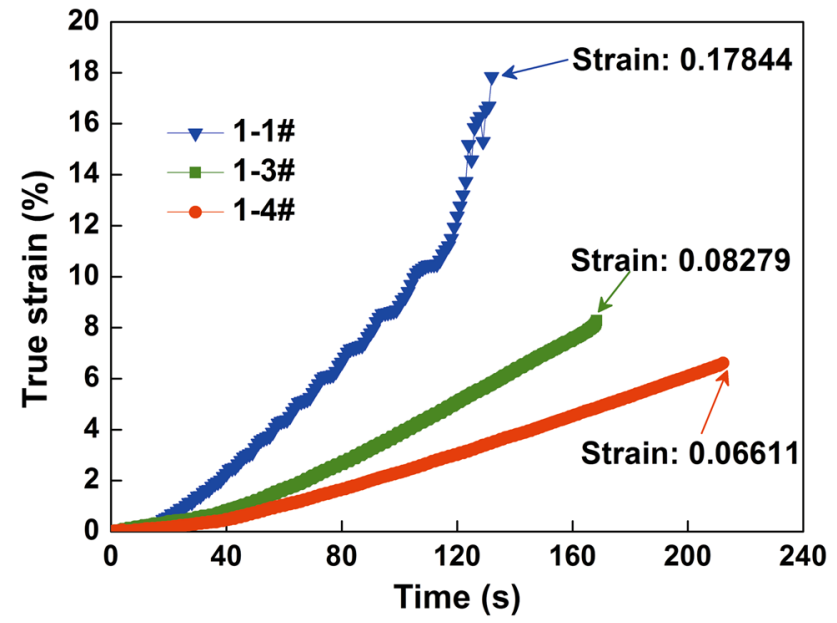

Fig. 11 True strain curves of the crack initiation points during the tensile test

the joint are significantly improved after the post-weld heat treatment.

Under the stress of $430 \mathrm{MPa}$, the specimens after the postweld heat treatment with (Fig. 12d) and without (Fig. 12e) weld reinforcements are compared. The weld reinforcements cause concentrated stress around the weld toe, and there is a more concentrated strain in the direction of the lateral extension of the weld toe. However, this phenomenon does not appear in the specimen without weld reinforcements (the deformation is more uniform in each region). For the specimen without weld reinforcements after the post-weld heat treatment (Fig. 12e), WZ has the lowest strain values compared to other regions. The relatively disordered grain morphology in WZ could make it relatively difficult for the slipping of dislocations. These dislocations accumulate around the grain boundaries and cause the certain reaction forces to the dislocation sources, thus causing the hardening of WZ. Therefore, the fracture strain in WZ is the lowest and the crack exactly initiates in it.

\section{Conclusions}

In this work, 2219 aluminum alloy butt-welded plate joints were obtained by "DCTIG + VPTIG + VPTIG" and some specimens from the joints were treated with "solid solution + artificial aging." Microstructure, mechanical properties and the role of weld reinforcement of the welded joints before and after the post-weld heat treatment were investigated. The conclusions drawn from this study are as follows:

1. After the post-weld heat treatment, both the amount and the size of the eutectic structure or $\theta$ phases are decreased. Correspondingly, the $\mathrm{Cu}$ content in $\alpha$-Al 

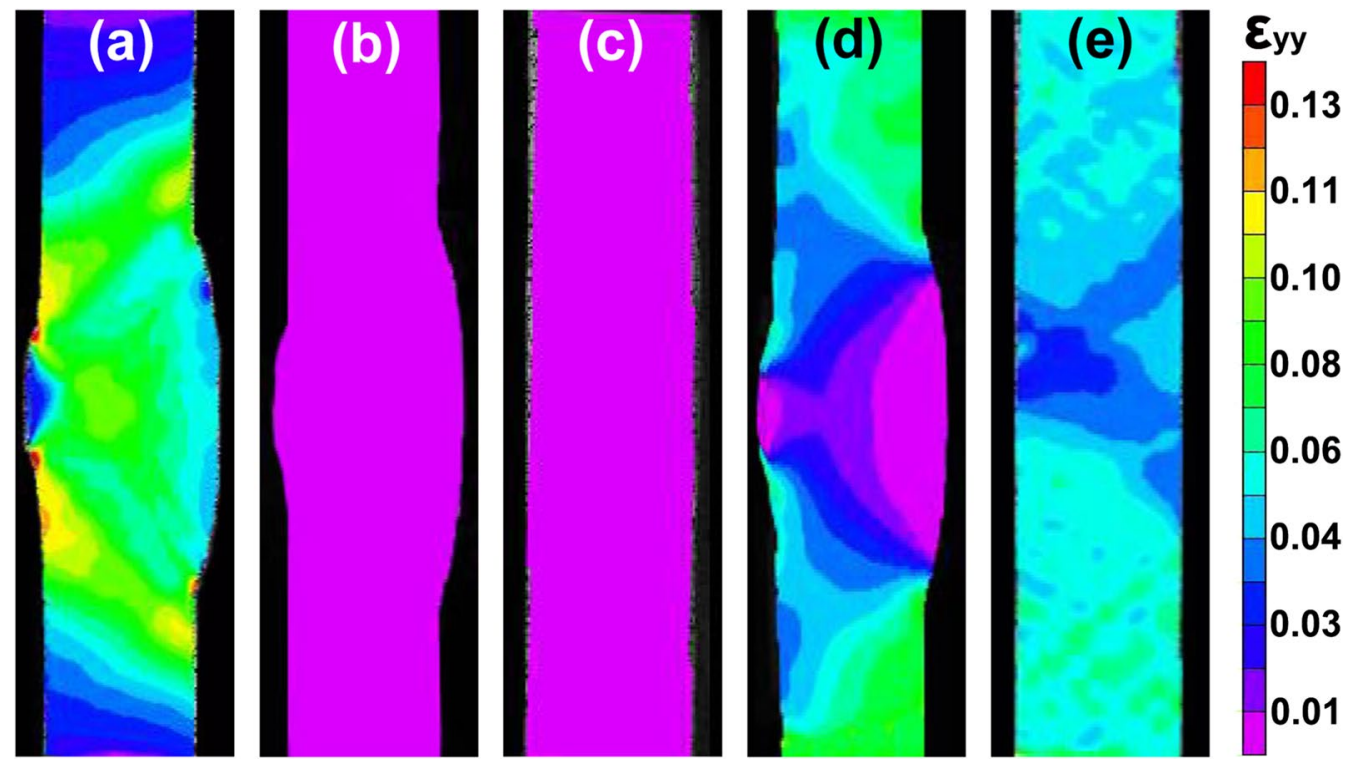

Fig. 12 True strain distributions on the edge surface under different stresses during the tensile test: $\mathbf{a}, \mathbf{b}, \mathbf{c}$ 1-1\#, 1-3\#, 1-4\# specimens under stress of $300 \mathrm{MPa}$, respectively; d, e 1-3\#, 1-4\# specimens under stress of $430 \mathrm{MPa}$, respectively

matrix and the microhardness values increase to a similar level in each region of the joint. The mechanical properties of the transverse joint become relatively homogeneous. Post-weld heat treatment plays a role of solid solution strengthening and aging strengthening.

2. The welded joints have different tensile properties mainly due to different weld shapes. However, after the post-weld heat treatment, the tensile strength of the joints with different weld shapes has the similar tensile strength (443-447 MPa), which is close to the tensile strength of the base metal. This is attributed to the relatively homogeneous and the improved mechanical properties in each region of the joints.

3. After the post-weld heat treatment, weld reinforcements have lost the reinforcing effect on WZ. The joint without weld reinforcements after the post-weld heat treatment has the optimal tensile properties, and the specimens randomly crack in WZ.

4. Post-weld heat treatment results in the precipitation of many $\theta^{\prime}$ phases in $\alpha$-Al matrix. These tiny $\theta^{\prime}$ strengthening phases cause complex stress fields and block the slipping of dislocations. Eventually, the specimens after the post-weld heat treatment are strengthened and the strain values are reduced (when under the equal stress).

Acknowledgement This work was supported by the Joint Funds of the National Natural Science Foundation of China (Grant No. U1637601).

\section{References}

[1] H.L. He, Y.P. Yi, S.Q. Huang, Y.X. Zhang, Mater. Charact. 135, $18(2018)$

[2] X.G. Zhang, L.Q. Li, Y.B. Chen, Z.J. Yang, Y.L. Chen, X.J. Guo, Materials 10, 1091 (2017)

[3] R.P. Naga, R.K. Srinivasa, G.M. Reddy, M. Kamaraj, R.K. Prasad, Mater. Sci. Eng. A 464, 192 (2007)

[4] V.M.J. Sharma, K.S. Kumar, B.N. Rao, S.D. Pathak, Mater. Sci. Eng. A 502, 45 (2009)

[5] Y.T. Lin, M.C. Wang, Y. Zhang, Y.Z. He, D.P. Wang, Mater. Des. 113, 54 (2017)

[6] B.S. Nair, S. Rakesh, G. Phanikumar, K.P. Rao, P.P. Sinha, Mater. Des. 31, 4943 (2010)

[7] C.S. Paglia, R.G. Buchheit, Mater. Sci. Eng. A 429, 107 (2006)

[8] H.B. Chen, J.F. Wang, G.D. Zhen, S.B. Chen, T. Lin, Mater. Des. 86, 49 (2015)

[9] H.J. Liu, H.J. Zhang, L. Yu, Mater. Des. 32, 1548 (2011)

[10] A.C. Nunes, E.O. Bayless, C.S. Jones, P.M. Munafo, A.P. Biddle, W.A. Wilson, Weld. J. 63, 27 (1984)

[11] Z.W. Lai, Z.Y. Huang, C. Pan, H.Q. Du, X.G. Chen, L. Liu, W.M. Long, G.S. Zou, Acta Metall. Sin. (Engl. Lett.) (2019). https://doi.org/10.1007/s40195-018-0749-X

[12] Z.Y. Feng, X.J. Di, S.P. Wu, D.P. Wang, X.Q. Liu, Acta Metall. Sin. (Engl. Lett.) 31, 263 (2018)

[13] L.Q. Niu, X.Y. Li, L. Zhang, X.B. Liang, M. Li, Acta Metall. Sin. (Engl. Lett.) 30, 438 (2017)

[14] C. Huang, F.F. Wang, D.Y. Yan, D.B. Liu, Z.G. Hu, Aerosp. Mater. Technol. 48, 56 (2018)

[15] S. Malarvizhi, V. Balasubramanian, Weld. World 56, 105 (2012)

[16] B.Q. Cong, B.J. Qi, X.G. Zhou, J. Luo, Trans. China Weld. Inst. 31, 85 (2010) 
[17] G.Q. Wang, Q. Li, Y.J. Li, A.P. Wu, N.X. Ma, D.Y. Yan, H.Q. Wu, Trans. Nonferrous Met. Soc. China 27, 10 (2017)

[18] D.K. Zhang, Q. Li, Y. Zhao, X.L. Liu, J.L. Song, G.Q. Wang, A.P. Wu, J. Mater. Eng. Perform. 27, 2938 (2018)

[19] M.P. John, Metall. Mater. Trans. A Phys. Metall. Mater. Sci. 12, $269(1981)$
[20] H.M. Wang, Y.P. Yi, S.Q. Huang, J. Alloys Compd. 690, 446 (2017)

[21] Q. Li, A.P. Wu, Y.J. Li, G.Q. Wang, D.Y. Yan, J. Liu, Mater. Sci. Eng. A 623, 38 (2015)

[22] J.M. Papazian, Metall. Trans. A 12(2), 269 (1981) 